\section{Structure of Octadecatrienoic Acid in Pine Seed Oil}

\author{
Shun Noguch, Toshiko KaTada. \\ and Kinji GoNDA* \\ Kyoritsu Women's University, *Institute of \\ Applied Microbiology, University of Tokyo
}

Received December 14, 1976

Several isomers were reported among natural octadecatrienoic (C18:3) acids. ${ }^{1 \sim 8)}$ In a previous study, ${ }^{7)}$ it was found that pine seed oil contains an unidentified octadecatrienoic acid in amounts of about $15 \%$ or more which had so far been erroneously considered to be $9,12,15-\mathrm{C} 18: 3$ acid. In view of its gaschromatographic and mass-spectrometric properties, this acid was considered tentatively as 6,9,12-C18: 3 ( $\gamma$-linolenic) acid in the previous paper.7) By further detailed gaschromatographic inspection, however, this acid was found to have slightly different retention parameters from those of $\gamma$-linolenic acid and it was intended in the present work to elucidate the structure of this acid by the use of proton magnetic resonance technique.

Preparation of methyl ester of the C18:3 acid. Ground pine seeds were extracted with a chloroformmethanol $(1: 1)$ mixture and the extract was subjected to evaporation under reduced pressure. The residue was methylated as usual and the methyl ester mixture was treated in methanol with urea $^{7,8)}$ several times until the mother liquor became rich in the C18: 3 acid (ca. $90 \%$ or more) with a minor amount of methyl 9,12-octadecadienoate.

The oxidation product. The C18: 3 acid in benzene was oxidized by a potassium permanganate-sodium carbonate aqueous solution at room temperature. The oxidation product was methylated and analysed by gaschromatography using $2 \mathrm{~m}$ DEGS column at $100^{\circ} \mathrm{C}$.

Standard preparations. Methyl esters of 9-octadecenoic, linoleic, $\alpha$-linolenic, $\gamma$-linolenic, 5,8,12,16docosatetraenoic, and 4,7,10,13,16,19-eicosahexaenoic acids were obtained from Applied Science Laboratories, Inc. (State College, Pa.).

NMR measurement. NMR spectra of the preparations dissolved in $\mathrm{CDCl}_{3}$ were obtained at $23^{\circ} \mathrm{C}$ with a $100 \mathrm{MHz}$ High Resolution NMR Spectrometer (Model JEOL 4H-100) by using TMS as an internal standard.

The gas chromatogram of the oxidation product of the $\mathrm{C18:3}$ acid revealed the formation of caproic

\section{(I)}

$M_{1}$ C C C B A A D A A B B A A B X BI

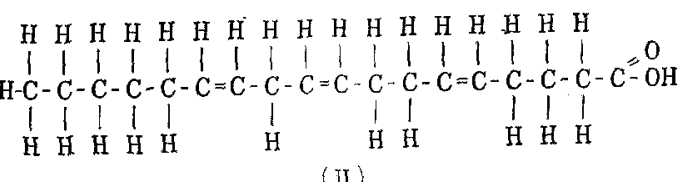

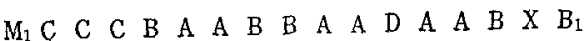
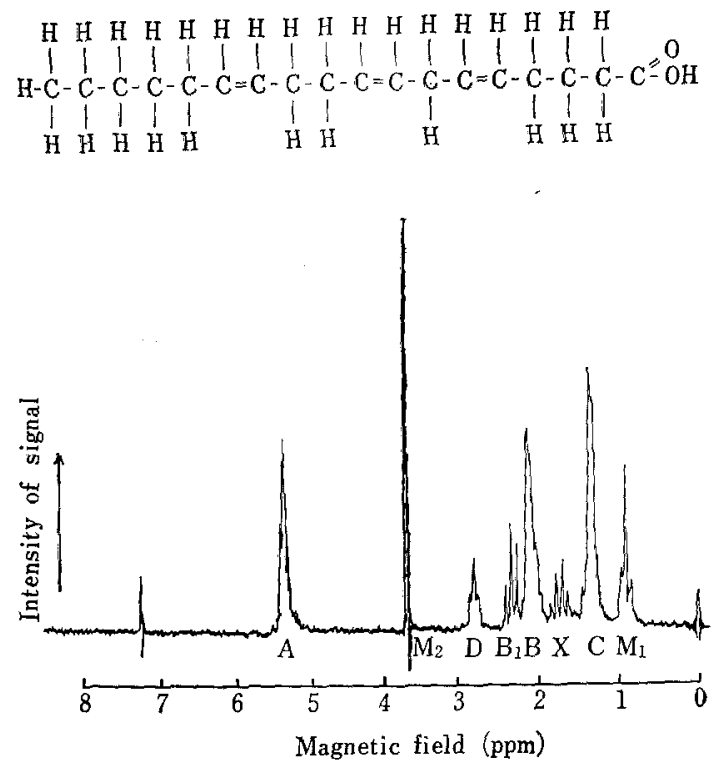

FIG. 1. NMR Spectrum of Methyl Ester of the C18: 3 Acid.

(hexanoic) acid, indicating the presence of $\mathrm{CH}_{3}-\left(\mathrm{CH}_{2}\right)_{4}$ $-\mathrm{CH}=\mathrm{CH}-$ group in the chain.

The NMR spectrum of methyl ester of this unidentified C18: 3 acid is shown in Fig. 1. The assignment of the signals was performed by way of the comparison of the shifts with those of the known signals of the standards. The signal referred to as $-\mathrm{X}$ - does not appear in usual unsaturated fatty compounds and is presumably ascribed to $\beta$-methylene protons affected by a double bond between $\mathrm{C}-5$ and $\mathrm{C}-6$, because the -X- signal, triplet-triplet, which is attributed to $\mathrm{X}$ proton coupled by $B$ and $B_{1}$ protons with $6 \mathrm{~Hz}$ coupling constant, is shifted slightly toward lower magnetic field as compared to that of the ordinary $\beta$-methylene proton and found only in the spectrum of methyl $5,8,11,14$-eicosatetraenoate among the standards used. The signal of $\beta$-methylene protons at $1.71 \mathrm{ppm}$ is never compatible with the presence of double bond located at $\mathrm{C}-3$. In addition, since the signal of the $\beta$-methylene proton affected by the presence of a double bond between $\mathrm{C}-4$ and $\mathrm{C}-5$ as in 4,7,10,13,16,19-eicosahexaenoate was shifted considerably further toward lower field, the possibility of the double bond being 
located at the $\mathrm{C}-4$ position is excluded. Furthermore, since no signal of $-\mathrm{CH}_{2}-\mathrm{C}=\mathrm{C}$ appeared at magnetic field lower than $\delta=5.5 \mathrm{ppm}$, there is no evidence for the presence of conjugated double bonds and the possibility of being $8,10,12$ - or $9,11,13$-octadecatrienoic acid is thus ruled out.

The number of methylene protons (D) between two double bonds is approximately two and proves the presence of one such methylene group in this acid. On the other hand, the signal of the protons $(B)$ on the carbon adjacent to a double bond is superimposed with the neighboring signal shifted slightly to lower field which would be caused by the presence of the protons on the ethylene group between two double bonds.

Accordingly, this C18: 3 acid must have a structure containing a double bond between $\mathrm{C}-5$ and $\mathrm{C}-6$, a methylene group between two double bonds, and an ethylene group between another pair of double bonds. Consequently, position of the third double bond is estimated to be between $\mathrm{C}-12$ and $\mathrm{C}-13$. The above estimation rejects the possibility of $6,10,14-$ acid. Therefore, all the evidences thus far obtained indicate that this acid would be either 5,9,12-(I) or 5,8,12-octadecatrienoic acid (II).

Although the preparation of this acid contains small amounts of 9,12-octadecadienoic acid, the intensity of each signal seems to be in good agreement with the structures estimated above. In this connection, Lehtinen et al. ${ }^{57}$ had obtained an isomer of octadecatrienoic acid from pine tall oil, oxidized the acid with $\mathrm{O}_{3}$ to result in a mixture containing caproic, malonic, succinic and glutaric acids, and concluded the acid to be 5,9,12-octadecatrienoic acid. However, since those oxidized products, i.e., caproic, malonic, succinic and glutaric acids, were also obtainable from the 5,8,12- isomers, it is apparent that the assignment mentioned above is premature.

Although it is impossible to decide from NMR studies whether this acid corresponds to $5,9,12-$ or $5,8,12$-isomer, the sequence such as $-\mathrm{CH}=\mathrm{CH}-\mathrm{CH}_{2}-$ $\mathrm{CH}=\mathrm{CH}-\mathrm{CH}_{2}-\mathrm{CH}_{2}-\mathrm{CH}=\mathrm{CH}-$ is unique among the natural $\mathrm{C} 18: 3$ acids and it seems worthwhile studying this acid from physiological and nutritional points of view.

The authors are indebted to Misses Emiko Imajo and Ranko Motojima for their skilled technical assistance.

This work is supported in part by Grant in Aid for Scientific Research from The Ministry of Education.

\section{REFERENCES}

1) G. R. Jamieson and E. H. Reid, Phytochemistry, 8, 1489 (1969).

2) D. Tyrrell, Can. J. Microbiol., 13, 755 (1967),

3) K. S. Markley, "Fatty Acids," 2nd ed. Interscience, New York, (1960).

4) Y. Aho, O. Harva and S. Nikkila, Teknillisen Kemian Aikakauslehti, 19, 390 (1962) [C.A. 58, 1627h (1963)].

5) O. Lehtinen, V. J. Karkkainen and M. Antila, Suomen Kemistilehti, 35B, 179 (1962) [C. A. 58, 2564f (1963)].

6) H.P. Kaufmann und J. Barve, Fette, Seifen, Anstrichmittel, 67(1), 14 (1965).

7) J. Iyoda and S. Noguchi, J. Home Econ., 24, 169 (1973).

8) D. Swern and W. E. Parker, J. Am. Oil Chem. Soc., 30, 5 (1953). 